\title{
Paul Verlaine, Sagesse
}

\section{Mario Richter}

\section{(2) OpenEdition}

\section{Journals}

\section{Edizione digitale}

URL: https://journals.openedition.org/studifrancesi/26673

DOI: 10.4000/studifrancesi.26673

ISSN: 2421-5856

\section{Editore}

Rosenberg \& Sellier

\section{Edizione cartacea}

Data di pubblicazione: 1 avril 2007

Paginazione: 205-206

ISSN: 0039-2944

\section{Notizia bibliografica digitale}

Mario Richter, «Paul Verlaine, Sagesse», Studi Francesi [Online], 151 (LI | I) | 2007, online dal 30

novembre 2015, consultato il 23 novembre 2021. URL: http://journals.openedition.org/studifrancesi/ 26673 ; DOI: https://doi.org/10.4000/studifrancesi.26673

\section{Questo documento è stato generato automaticamente il 23 novembre 2021.}

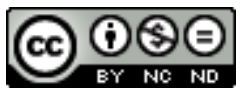

Studi Francesi è distribuita con Licenza Creative Commons Attribuzione - Non commerciale - Non opere derivate 4.0 Internazionale. 


\title{
Paul Verlaine, Sagesse
}

\author{
Mario Richter
}

\section{NOTIZIA}

PAUL VERLAINE, Sagesse, édition critique établie, annotée et présentée par Olivier Bivort, Le livre de Poche classique, 2006, pp. 348.

1 Chi voglia accostarsi utilmente al Verlaine di Sagesse non potrà trovare nulla di meglio di questa edizione. In una sostanziosa introduzione Olivier Bivort gli fornisce con estrema chiarezza tutte le ragioni che hanno portato Verlaine alla pubblicazione di questa raccolta religiosa dal carattere composito. «Mêlant 'impressions' et 'oraisons' scrive il critico - le recueil témoigne de l'évolution poétique de Verlaine depuis les Romances sans paroles dans le sens du lyrisme et de la subjectivité. Son caractère composite, comme tous les volumes de verlaine à partir des années 1880, lui garantit une unité qui transcende les époques, les déclarations, les programmes».

2 L'allestimento del testo (la cui base è costituita dall'edizione originale e non dall'ultima, come si è usato fare) è davvero encomiabile per completezza e per precisione. Oltre alle varianti, che gli consentono di seguire il movimento del testo, il lettore può trarre un largo profitto dalla ricca annotazione, sempre puntuale e pertinente. Di grande utilità sono anche le pagine dedicate alla "Réception de l'œuvre", seguite da una "Chronologie" e dalla preziosa "Bibliographie". 